\title{
Apoptosis is not an invariable component of in vitro models of cortical cerebral ischaemia
}

\author{
Paul Alexander JONES ${ }^{1 *}$, Gillian Ruth MAY², Joyce Ann MCLUCKIE ${ }^{1}$, Akinori IWASHITA³ ${ }^{3}$ John SHARKEY ${ }^{1}$ \\ ${ }^{1}$ Fujisawa Institute of Neuroscience, Division of Neuroscience, University of Edinburgh, 1 George Square, Edinburgh, UK. \\ ${ }^{2}$ Medical Information, Eli Lilly and Company Ltd, Lilly House, Priestley Road, Basingstoke, RG24 9NL, UK. \\ ${ }^{3}$ Medicinal Biology Research Laboratories, Fujisawa Pharmaceuticals Co. Ltd., 2-1-6 Kashima, Yodogawa-ku, Osaka, 532-5814, Japan.
}

\begin{abstract}
Characterising the mechanisms of cell death following focal cerebral ischaemia has been hampered by a lack of an in vitro assay emulating both the apoptotic and necrotic features observed in vivo. The present study systematically characterised oxygen-glucose-deprivation (OGD) in primary rat cortical neurones to establish a reproducible model with components of both cell-death endpoints. OGD induced a time-dependent reduction in cell viability, with $80 \%$ cell death occurring $24 \mathrm{~h}$ after $3 \mathrm{~h}$ exposure to $0 \% \mathrm{O}_{2}$ and $0.5 \mathrm{mM}$ glucose. Indicative of a necrotic component to OGDinduced cell death, N-methyl-D-aspartate (NMDA) receptor inhibition with MK- 801 attenuated neuronal loss by $60 \%$. The lack of protection by the caspase inhibitors DEVD-CHO and z-VAD-fmk suggested that under these conditions neurones did not die by an apoptotic mechanism. Moderating the severity of the insult by decreasing OGD exposure to $60 \mathrm{~min}$ did not reduce the amount of necrosis, but did induce a small degree of apoptosis (a slight reduction in cell death was observed in the presence of $10 \mu \mathrm{M}$ DEVD-CHO). In separate experiments purported to enhance the apoptotic component, cells were gradually deprived of $\mathrm{O}_{2}$, exposed to $4 \% \mathrm{O}_{2}$ (as opposed to $0 \%$ ) during the OGD period, or maintained in serum-containing media throughout. While NMDA receptor antagonism significantly reduced cortical cell death under all conditions, a caspase-inhibitor sensitive component of cell death was not uncovered. These studies suggest that OGD of cultured cortical cells models the excitotoxic, but not the apoptotic component of cell death observed in vivo.
\end{abstract}

Keywords: oxygen-glucose-deprivation, caspase, cortical, necrosis.

\section{INTRODUCTION}

The involvement of apoptotic cell death alongside necrosis within in vivo models of focal cerebral ischaemia has been observed in a number of reports over the last few years[1-8], with only a few animal studies failing to find apoptotic indices[9, 10]. The potential for therapies targeted against it have driven the investigations to elucidate the cascade of events which characterises apoptosis associated with ischaemia[11-13]. Complementary studies examining similar phenomena in vitro would be hugely beneficial to progress in this area, as well as potentially providing means for the screening of compounds by the pharmaceutical industry. However, converting the in vivo ischaemia model with facets of apoptosis and necrosis, into a culture dish have proved less than straight forward. While some studies have suggested indications of apoptosis [14-16] following combined oxygen-glucose-deprivation

\footnotetext{
${ }^{*}$ Correspondence: Paul Alexander JONES,

Tel: +44 (0)131-6511897, Fax: +44 (0)131-6679381

E-Mail: P.Jones@ed.ac.uk
}

(OGD) in vitro, it has yet to be properly characterized.

The objective of the current study was to examine the cell death processes of OGD in rat cerebrocortical neurone cultures, exposing both necrotic and apoptotic components corresponding to that which is reported to occur in the salvageable (penumbral) regions of the ischaemic brain in vivo[17]. A systematic approach was employed, characterising OGD cell death before modifying aspects of the protocol and the severity of the insult. The study is comprehensive in its conclusion that OGD is a good model of the excitotoxic, but not the apoptotic constituent of cell death in cortical cultures.

\section{MATERIALS AND METHODS}

\section{Primary culture}

Primary cultures of rat cerebrocortical neurones were prepared using a method adapted from Pauwels et al[18]. Briefly, the cortices from embryonic day 17 Sprague-Dawley rats were dissociated for 12 min in Hank's Balanced Salt Solution (HBSS without $\mathrm{Ca}^{2+}$ and $\mathrm{Mg}^{2+}$ ) containing $0.09 \%$ trypsin and $500 \mathrm{IU} / \mathrm{ml}$ DNase, triturated in HBSS containing $500 \mathrm{IU} / \mathrm{ml}$ DNase and plated out at $1600 \mathrm{cells} / \mathrm{mm}^{2}$ 
in Neuronal Plating Medium (containing $5 \%$ heat-inactivated horse serum, $5 \%$ heat-inactivated foetal bovine serum) onto poly-D-lysinecoated $15 \mathrm{~mm}$ wells. After $24 \mathrm{~h}$, the medium was replaced with fresh, serum-free B27 medium. The neuronal cultures were further purified by treatment with cytosine arabinoside $5 \mu \mathrm{M}$ at $5-7 \mathrm{~d}$ in vitro (DIV) to give cultures that were reliably $99 \%$ (B27-treated) or $98 \%$ (NCDM-treated) neuronal (as determined by GFAP positive and negative cell counts; data not shown). Thereafter the medium was partly refreshed twice weekly. Unless otherwise indicated, cultures were used for experimentation at 11-15 DIV. Care of all animals was in accordance with the UK Animals (Scientific Procedures) Act 1986.

\section{Caspase activity}

Cells were collected and pelleted in ice-cold phospho-buffered saline (PBS). Drained pellets were extracted in $25 \mu$ l extraction buffer (10 mM HEPES-KOH pH 7.4; $50 \mathrm{mM} \mathrm{KCl,} 2 \mathrm{mM} \mathrm{MgCl}_{2}, 5 \mathrm{mM}$ EGTA; $0.5 \%$ CHAPS; $1 \mathrm{mM}$ phenylmethylsulphonyl fluoride (PMSF); $10 \mu \mathrm{g} / \mathrm{ml}$ pepstatin A, leupeptic, aprotinin; $1 \mathrm{mM}$ dithiothreital (DTT)) on ice for 20-30 min followed by a freeze-thaw cycle. Nuclear and insoluble material was removed by centrifugation (30 min, 10,000 rpm at $4^{\circ} \mathrm{C}$ ). Supernatants were diluted (1:8) with dilution buffer (25 mM HEPES-KOH pH 7.4; $50 \mathrm{mM} \mathrm{NaCl} ; 5 \mathrm{mM}$ EGTA; 0.1\% CHAPS; $10 \mathrm{mM}$ DTT; $10 \%$ sucrose) and protein concentration determined. Caspase activity was assayed using $20 \mu \mathrm{M}$ fluorescent aminomethylcoumarin-peptide substrates (Peptide Institute Inc., Japan) for caspase-1-like (Ac-YVAD-AMC) and caspase-3like (Ac-DEVD-AMC) enzymes. Inhibition of respective enzyme activities was assessed using $200 \mathrm{nM}$ reversible aldehyde inhibitors Ac-YVAD-CHO or Ac-DEVD-CHO, for caspase-1-like and caspase-3like enzymes respectively. Extracts were also made from cultures that had not had any treatment in order to determine whether there was any caspase activation in control cultures at various stages. Except where stated the protein concentration of the extracts were determined using a bicinchoninic acid (BCA) protein assay Kit (Pierce) and the concentration adjusted.

\section{NMDA-induced neurotoxicity}

Cultures were exposed to NMDA $\left(10^{-4} \mathrm{M}\right.$, Tocris $)$ in HEPESbuffered saline (mM: $\mathrm{NaCl} 51.3 ; \mathrm{KCl}$ 5.4; glucose 25; HEPES 20; $\mathrm{CaCl}_{2}$ 1.8; glycine 0.01 ; $\mathrm{pH} 7.3$ ) for 30 min after which time the cells were returned to complete culture medium (containing B27) for a further $23 \mathrm{~h}$. Drugs or appropriate vehicles were present throughout. At the end of the $24 \mathrm{~h}$ period, cell viability was assessed by determination of lactate dehydrogenase extrusion (LDH) using the Promega Cytotox $96^{\circledR}$ non-radioactive cytotoxicity assay (as per instructions). Colour change was detected with a Dynex Technologies MRX spectrophotometer plate reader.

\section{Staurosporine-induced neurotoxicity}

Staurosporine (STS) was made up in dimethylsulphoxide (DMSO) and then diluted into NCDM, so that the final concentration of DMSO was $0.1 \%$. Cultures were exposed to STS $\left(10^{-8}-10^{-5} \mathrm{M}\right)$ for $24 \mathrm{~h}$ after which time cell survival was assessed by the reduction of 3-(4,5-dimethylthiazol-2-yl)-2,5-diphenyl tetrasolium bromide (MTT) to a coloured formazan product by viable cells. MTT (Sigma, UK) was added to the cell to give a final concentration of $0.3 \mathrm{mg} / \mathrm{ml}$ and incubated at $37^{\circ} \mathrm{C}$ for $2-4 \mathrm{~h}$ in a humidified $95 \% / 5 \% \mathrm{O}_{2} / \mathrm{CO}_{2}$ atmosphere. $100 \mu \mathrm{l}$ isopropanolol/0.04 N HCl was added before measured on a Dynex Technologies MRX spectrophotometer plate reader (at $570 \mathrm{~nm}$ with a reference wavelength of $630 \mathrm{~nm}$ ). Assessment of caspase activation (as an indicator of apoptotic cell death) was carried out using cell extracts from cultures exposed to STS or vehicle.

\section{Oxygen-glucose deprivation}

Cultures were exposed to a variety of ischaemic-like conditions (oxygen-, glucose- or combined oxygen-glucose-deprivation) for various time periods. All experiments were conducted in Neurobasal medium supplemented with $0.5 \mathrm{mM}$ L-glutamine. For normoglycaemic conditions the cells were maintained in media containing 25 $\mathrm{mM}$ glucose. For experiments requiring aglycaemic media, the glucose concentration was either 0.5 or $0 \mathrm{mM}$ (as stated for each experiment). If required, appropriate solutions were made anoxic by placing them into an anaerobic workstation (don Whitley Scientific MACS VA set to run under anaerobic conditions with $5 \% \mathrm{CO}_{2}$ at $37^{\circ} \mathrm{C}$ ) and bubbling with $95 \% \mathrm{~N}_{2} / 5 \% \mathrm{CO}_{2}$ for at least $30 \mathrm{~min}$. Wells were washed with $0.5 \mathrm{ml}$ of the appropriate medium and then incubated with $0.25 \mathrm{ml}$ of the appropriate medium for the time periods indicated in either the anaerobic workstation (oxygen- and combined oxygen-glucose-deprived cells) or the normoxic incubator (control and glucose-deprived cells). At the end of the appropriate period, the cultures were removed from the respective incubator and media replaced with normoglycaemic media. The cells were placed in the normoxic incubator for the remainder of the recovery period. For MAP-2 immunostaining, cells were fixed in paraformaldehyde-lysine phosphate buffered (PLP) fixative for $20-30 \mathrm{~min}$ prior to $0.25 \%$ Triton permeabilisation. Cells were incubated in MAP-2 primary antibody (Santa-Cruz, USA) at 1:100 for $2 \mathrm{~h}$. After washing in PBS FITC labelled secondary antibody (FITC-conjugated anti-mouse IgG; Santa-Cruz, USA) was added at 1:64 dilution. Fluorescence was read with a Labsystems Fluoroskan Ascent plate reader.

\section{Gradual oxygen deprivation}

In the experiments described above, exposure to oxygen-deprivation was carried out by exchanging the medium of experimental cultures with previously de-oxygenated medium so that deprivation was instantaneous. In this gradual deprivation experiment however, oxygen depletion was allowed to occur over time by placing the cells (in $25 \mathrm{mM}$ glucose-containing Neurobasal medium plus appropriate drugs or vehicles) into the anaerobic incubator without any exchange of medium for $6 \mathrm{~h}$. The plates were then removed to the normoxic incubator and allowed to recover for $48 \mathrm{~h}$. Viability was assessed as before.

\section{Drug treatment}

Cultures were pre-treated for 30 or 90 min with drug or vehicle in normoxic Neurobasal medium containing $25 \mathrm{mM}$ glucose. The cultures were then exposed to various oxygen and glucose conditions for periods of time after which they were returned to normoxic $\left(20 \% \mathrm{O}_{2}\right) /$ normoglycaemic ( $25 \mathrm{mM}$ glucose) medium for $24 \mathrm{~h}$. Drugs or vehicles were present throughout the exposure and recovery periods.

(+)-5-methyl-10,11-dihydro-5H-dibenzo[a,d] cyclohepten-5, 10imine maleate (MK-801) and D(-)-2-amino-5-phosphonopentanoate (D-AP5; Tocris) were dissolved in sterile purified water prior to dilution into Neurobasal medium. 


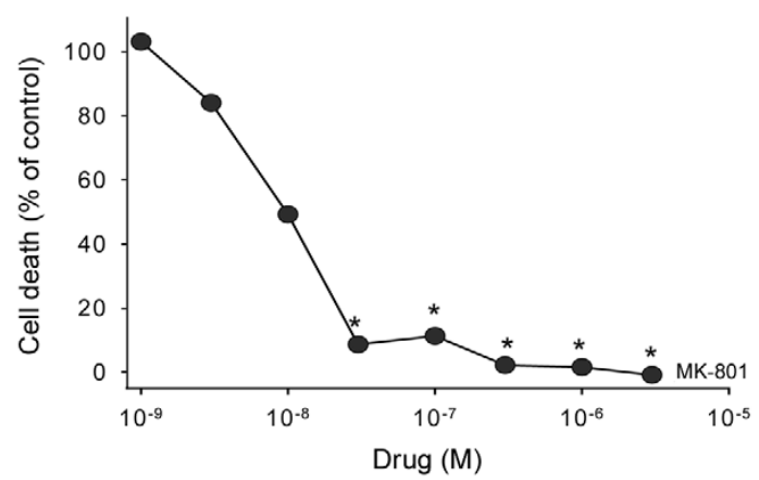

Fig 1. Pharmacological modification of NMDA-induced neurotoxicity in cultured rat cortical neurones. Cultures of rat cerebrocortical neurones (7 DIV; maintained in B27 medium) were pre-treated for $30 \mathrm{~min}$ with the compounds indicated prior to a $30 \mathrm{~min}$ exposure to $10^{-4} \mathrm{M}$ NMDA. Following NMDA exposure, the cultures were returned to complete culture medium for a further $24 \mathrm{~h}$. MK-801 was present throughout exposure and recovery periods. Cell death was assessed by measurement of LDH extrusion into the culture medium. *Value significantly different from control (one-way ANOVA on Rank's with post hoc Dunn's test, $\mathrm{p}<0.05$ ).

6, 7-dichloroquinoxaline-2, 3-dione (CNQX; Tocris), DEVD-CHO (cell permeable form, Calbiochem) and z-VAD-fmk (Enzyme Systems Products) were dissolved in anhydrous DMSO. Final concentrations of DMSO in experimental solutions were $0.05,0.5$ and $1 \%$ respectively.

\section{RESULTS}

\section{NMDA-induced neurotoxicity}

30 min exposure of N-methyl-D-aspartate (NMDA; $10^{-4}$ $\mathrm{M})$ to rat cortical neurones induced excitotoxic cell death over the following $24 \mathrm{~h}$. Pre-treatment with the NMDA receptor antagonist, MK801 $\left(>3 \times 10^{-8} \mathrm{M}\right)$ produced complete inhibition of NMDA-induced neurotoxicity (Fig 1).

\section{Staurosporine-induced neurotoxicity}

Staurosporine (STS) is a broad-based inhibitor of protein kinase $\mathrm{C}$ (PKC), which induces apoptosis in a wide variety of cell types including cerebrocortical neurones [19]. As can be seen in Fig 2, both STS $\left(3 \times 10^{-7}\right.$ and $\left.10^{-6} \mathrm{M}\right)$ and the vehicle $(0.1 \%$ DMSO) induced caspase activation of the caspase-3-like (but not the caspase -1-like) family as evidenced by cleavage of Ac-DEVD-AMC substrate but not Ac-YVAD-AMC substrate. It should be noted that for these studies, although equivalent cell numbers were present at the start of the experimental period, it is possible that non-equivalent cell numbers were recovered and extracted at the end of the experimental period (i.e. STS treatment will have resulted in cell death, and according to the stage of cell death, fewer cells may have been recovered). In all further studies, enzyme activities was
A

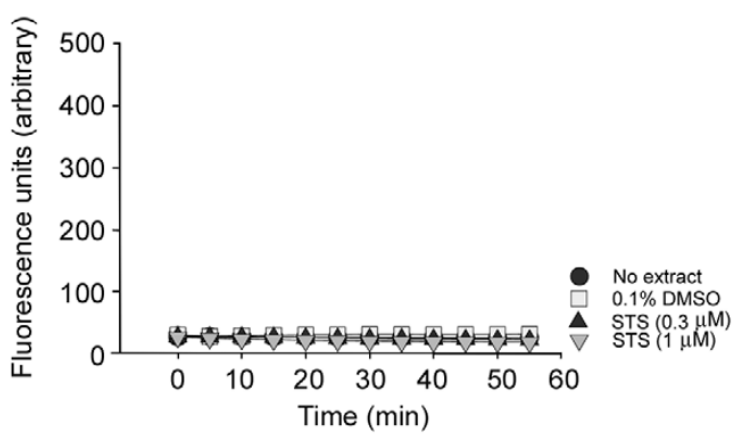

B

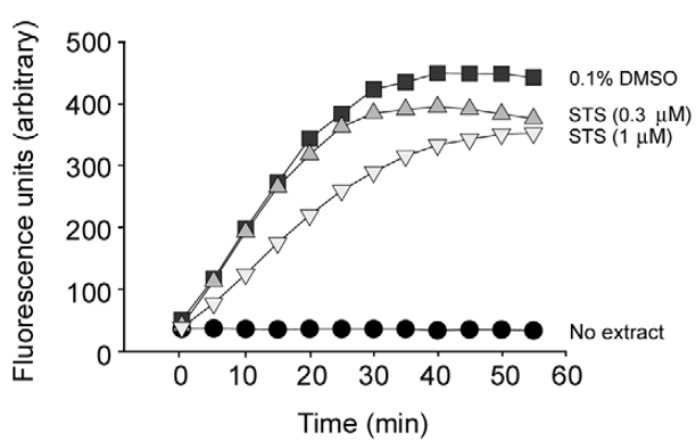

Fig 2. Stimulation of capase activity in rat cerebrocortical neurones by staurosporine and DMSO. Rat cortical neurones (11 DIV) were exposed to either $0.1 \%$ DMSO or staurosporine (STS) for $24 \mathrm{~h}$. Cells were then extracted and assayed for caspase activity of (A) caspase-1-like family (using Ac-YVAD-AMC) or (B) caspase-3-like family (using Ac-DEVD-AMC).

normalised to protein content of the extract, but as this required a protein assay able to withstand the constituents of the extraction buffer, this was not able to be performed for the present study.

\section{Effect of glucose concentration and exposure time on anoxia-induced cell death}

Dose-response relationships between glucose concentration revealed that the cultures could withstand exposure to glucose levels down to $0.5 \mathrm{mM}$ for up to $3 \mathrm{~h}$ without loss of viability (data not shown). Rat cortical cultures were subsequently exposed to either $0,0.5$ or $25 \mathrm{mM}$ glucose-containing Neurobasal medium in either normoxic ( $20 \%$ oxygen) or anoxic ( $0 \%$ oxygen) conditions for various times (Fig 3A, B). Under these conditions of varying glucose and oxygen levels, it appeared that the cultures were more sensitive to the removal of glucose than they were to the removal of oxygen - exposure to $0 \mathrm{mM}$ glucose produced profound cell death following exposure times as short as $3 \mathrm{~h}$ regardless of whether oxygen had been removed or not (Fig 3A). In contrast, removal of 
A

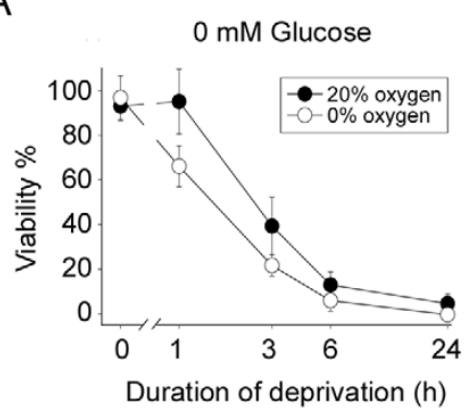

B

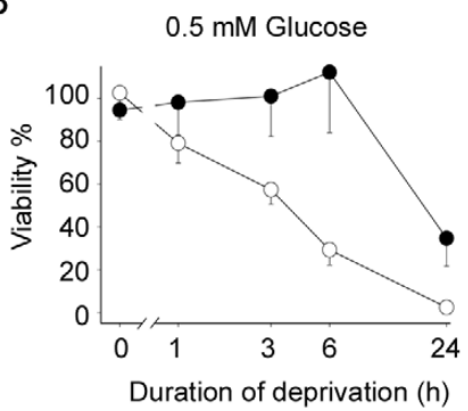

C

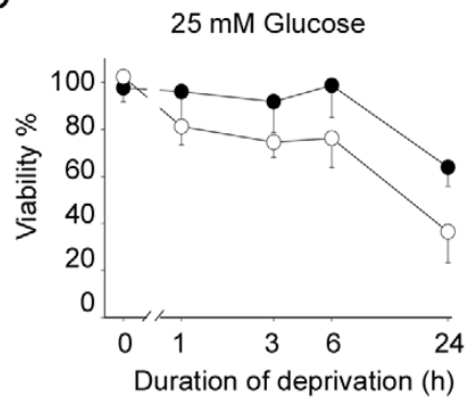

Fig 3. Glucose concentration and anoxia-induced cell death in cultured rat cortical neurones. Rat cortical cultures were exposed to 0 (A), 0.5 (B) or $25 \mathrm{mM}(\mathbf{C})$ glucose-containing Neurobasal Medium in either normoxic ( $20 \%$ oxygen) or anoxic ( $0 \%$ oxygen) conditions for the periods indicated. Following the exposure, cultures were returned to $25 \mathrm{mM}$ glucosecontaining, normoxic medium for a remainder of $24 \mathrm{~h}$ period, after which time viability was assessed by means of a MTT assay. Results shown are means \pm SD of 3 independent experiments comprising 14 wells in total.

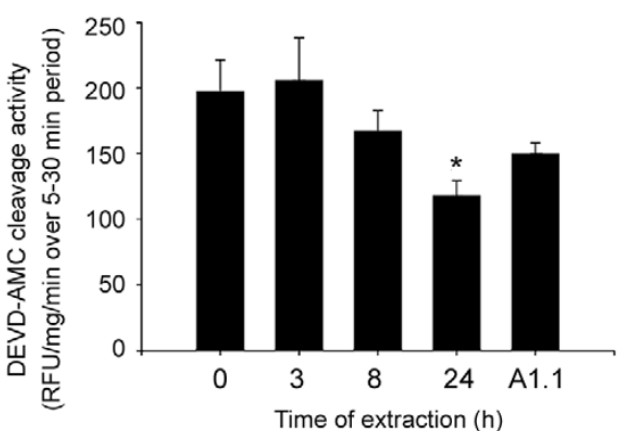

Fig 4. DEVD-AMC cleavage activity in cultured rat cortical neurones after $3 \mathrm{~h}$ OGD. Rat cortical cultures were exposed to $0.5 \mathrm{mM}$ glucose and $0 \%$ oxygen for $3 \mathrm{~h}$ and then returned to $25 \mathrm{mM}$ glucose, $20 \%$ oxygen for a further $21 \mathrm{~h}$. At the times indicated, cells were harvested and cytosolic extracts were made. The cell extracts were assayed for group- 2 caspase activity by measuring the cleavage of the fluorogenic substrate Ac-DEVD-AMC. Results shown represent means $\pm \mathrm{SE}$ of 3 separate experiments (comprising 9 data points in total). "Value significantly lower than the $0 \mathrm{~h}$ (control/untreated) group (One-way ANOVA with post-hoc Dunnett's test, $\mathrm{p}<0.05)$. A1.1 = extract from dexamethasone-treated A1.1 cells.

oxygen under conditions of normoglycaemia (Fig 3C) produced cell death that differed very little from normoxic controls. From this data a $3 \mathrm{~h}$ exposure to $0.5 \mathrm{mM}$ glucose and $0 \%$ oxygen was chosen for subsequent studies as this appeared to produce a loss of viability of approximately $50 \%$.

\section{Caspase activity following 3 h OGD treatment}

Rat cortical neurones were exposed to combined oxygen-glucose deprivation for $3 \mathrm{~h}\left(0 \% \mathrm{O}_{2}, 0.5 \mathrm{mM}\right.$ glucose $)$. The cultures were then returned to normoxic, normoglycaemic medium. Cells were harvested, extracted and assayed for group II caspase activity $0,3,8$ and $24 \mathrm{~h}$ later

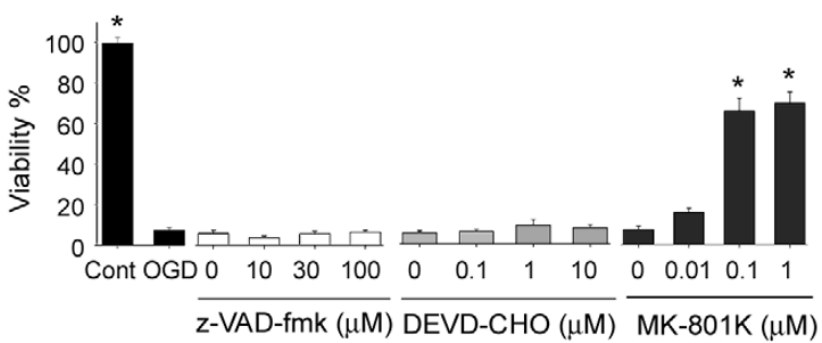

Fig 5. Pharmacological modification of $3 \mathrm{~h}$ OGD-induced cortical cell death. Rat cortical cultures were pre-treated for 90 min with drug or vehicle as indicated prior to a $3 \mathrm{~h}$ exposure to $0.5 \mathrm{mM}$ glucose, $0 \%$ oxygen. Following the exposure period cells were returned to $25 \mathrm{mM}$ glucose-containing, normoxic medium for $24 \mathrm{~h}$. Drugs or vehicles were present throughout the exposure and recovery periods. At the end of the recovery period viability was assessed by fluorescence quantification of FITC-linked MAP-2 immunohistochemistry. Results shown represent means \pm SE of 2 independent experiments comprising 5-9 wells in total. *Value significantly greater than OGD group (Kruskal-Wallis ANOVA on ranks with post-hoc Dunn's test, $\mathrm{p}<0.05)$.

(Fig 4).

The activity of caspase-3-like caspases did not increase with $3 \mathrm{~h}$ OGD (compared to the untreated cells extracted at $0 \mathrm{~h}$ ), producing instead a slight decrease at $24 \mathrm{~h}$. However, this result should be interpreted with caution as the activity in all extracts was similar in magnitude to that observed in dexamethasone-treated A1.1 cell extracts (used as a positive control in this system and thus regarded as substantial activity). The reason for these high group II caspase activities in rat cerebrocortical cultures is not clear, but could be due to ongoing cell death occurring in this primary culture system. Previous experiments with these cultures have shown similarly high baseline levels of caspase 
A

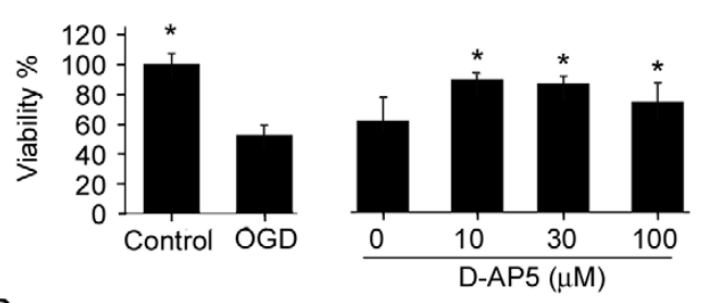

B

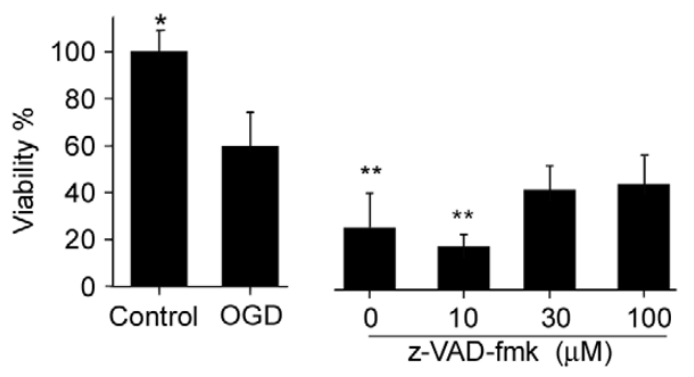

C

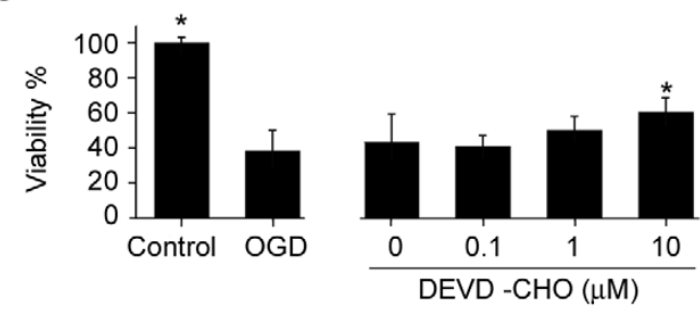

Fig 6. Pharmacological modification of 60 min OGD-induced cell death in cultured rat cortical neurones. Rat cortical cultures were pretreated for 90 min with different concentrations of (A) MD-AP5, (B) Z-VAD-fmk and (C) DEVD-CHO prior to a 60 min exposure to $0.5 \mathrm{mM}$ glucose, $0 \%$ oxygen. Following the exposure, cells were returned to $25 \mathrm{mM}$ glucose-containing, normoxic medium for $24 \mathrm{~h}$. Drugs or vehicles were present throughout the exposure and recovery periods. At the end of the recovery period, viability was assessed by means of fluorescence quantification of FITC-linked MAP-2 immunohistochemistry. Results shown represent the means $\pm \mathrm{SE}$ of 6 wells. "Value significantly greater than OGD group (9A: Kruskal Wallis ANOVA on ranks with post-hoc Dunnett's test, $\mathrm{p}<0.05$; 9B$\mathrm{C}$ : One-way ANOVA with post-hoc Tukey test, $\mathrm{p}<0.05){ }^{* *}$ Value significantly lower than OGD group (One-way ANOVA with post-hoc Tukey test, $\mathrm{p}<0.05)$.

activity even in cultures that had undergone no treatments (including sham washes; data not shown).

\section{Effect of MK801, DEVD-CHO and z-VAD-fmk on 3 h OGD treatment}

Exposure to $0.5 \mathrm{mM}$ glucose, $0 \%$ oxygen for $3 \mathrm{~h}$ produced approximately $80 \%$ cell loss (assessed using microtubule-associated protein-2 (MAP-2) immunohistochemistry after $24 \mathrm{~h}$; Fig 5). Addition of the NMDA receptor antagonist MK-801 $\left(10^{-8}-10^{-6} \mathrm{M}\right) 90 \mathrm{~min}$ prior to the onset of OGD significantly attenuated neuronal loss at

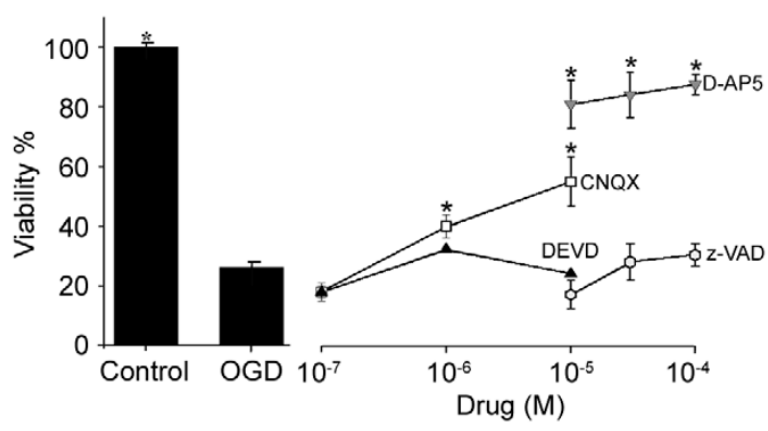

Fig 7. Pharmacological modification of cell viability after $6 \mathrm{~h}$ gradual oxygen deprivation in cultured rat cortical neurones. Cultures of rat cortical neurones were pre-treated for $30 \mathrm{~min}$ with the drugs indicated (where DEVD $=$ DEVD-CHO and $\mathrm{zVAD}=\mathrm{z}-\mathrm{VAD}-\mathrm{fmk}$ ) prior to gradual exposure to $0 \% \mathrm{O}_{2}$. No further medium exchanges or washes were carried out following this addition of drug-containing medium throughout the remainder of the experiment. Following $6 \mathrm{~h}$ exposure, the cultures were removed to a normoxic incubator and allowed to recover for $48 \mathrm{~h}$. Viability was then assessed using MAP-2 immunohistochemistry. Results shown represent the means $\pm \mathrm{SE}$ of 2-4 experiments comprising 12-24 wells. *Value significantly greater than OGD group (Kruskal Wallis ANOVA with post-hoc Dunn's test, $\mathrm{p}<0.05$ )

the two higher concentrations (Fig 5). In contrast, neither the broad acting caspase inhibitor z-VAD-fmk $\left(10^{-5}-10^{-4}\right.$ M; Fig 8), nor the specific group II caspase inhibitor DEVD-CHO $\left(10^{-7}-10^{-5} \mathrm{M}\right.$; Fig 5) had any effect. Similar results for MK-801 and the caspase inhibitors were observed when the MTT assay replaced MAP-2 immunohistochemistry as an end-point (data not shown).

\section{Effects of DEVD-CHO, z-VAD-fmk or D-AP5 on 60 min OGD treatment}

Decreasing the duration of OGD $\left(0 \% \mathrm{O}_{2}, 0.5 \mathrm{mM}\right.$ glucose) to $60 \mathrm{~min}$ consistently produced a $40-60 \%$ loss of neuronal viability (as measured by the fluorescence quantification of fluorescein isothiocyanate- (FITC-) linked MAP-2 immunohistochemistry after $24 \mathrm{~h}$; Fig 6A-C). Similarly to the previous experiment, the addition of an NMDA receptor antagonist (D-AP5) significantly prevented cell loss (Fig 6A). The caspase inhibitor, z-VAD-fmk $\left(10^{-5}\right.$ $\left.10^{-4} \mathrm{M}\right)$ again had no effect, while the group II caspase inhibitor, DEVD-CHO (cell permeable form) produced a significant but small effect at the highest dose examined $\left(10^{-5} \mathrm{M}\right.$; Fig 6B, C).

\section{Gradual oxygen deprivation}

Gradual exposure to oxygen (but not glucose) deprivation for $6 \mathrm{~h}$ produced a $75-80 \%$ loss of viability at $48 \mathrm{~h}$ (Fig 7). This loss of viability was prevented by those compounds acting at excitatory amino acid receptors (MK801: 
A

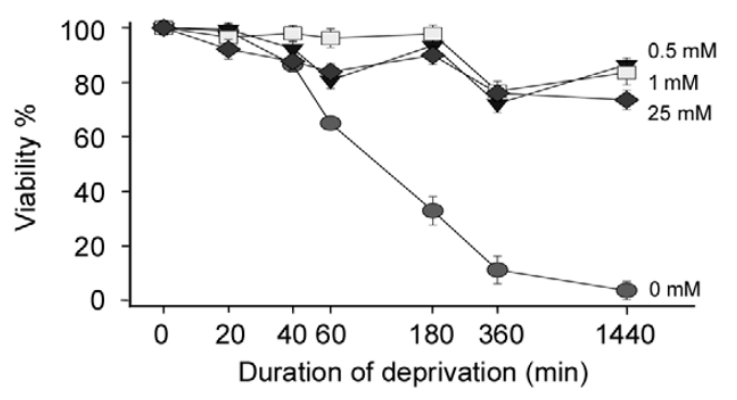

B

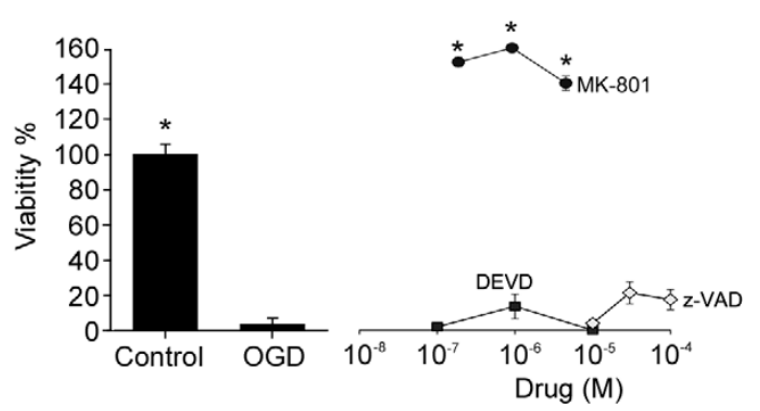

Fig 8. Cortical neurone viability under $4 \%$ oxygen with or without glucose deprivation. (A) Rat cortical cultures were exposed to 0, 0.5, 1 or $25 \mathrm{mM}$ glucose-containing Neurobasal medium in $4 \% \mathrm{O}_{2}$ for the times indicated. They were then returned to normoxic, $25 \mathrm{mM}$ glucose-containing Neurobasal for the remainder of a $24 \mathrm{~h}$ period after which viability was assessed as previously described. Results shown represent means \pm SE of 3 experiments (16-18 wells). (B) Cultures were pre-treated with the drugs indicated (where DEVD=DEVD$\mathrm{CHO}$ and $\mathrm{zVAD}=\mathrm{z}-\mathrm{VAD}-\mathrm{fmk}$ ) for $30 \mathrm{~min}$ prior to $3 \mathrm{~h}$ exposure to $4 \% \mathrm{O}_{2}$ in glucose-free Neurobasal. Following the exposure period, cultures were returned to normoxic, normoglycaemic Neurobasal for $48 \mathrm{~h}$ prior to assessment of viability as previously described. Drugs were present throughout the exposure and recovery periods. Results show means \pm SE of 6-23 wells. *Value significantly greater than OGD group (Kruskal Wallis ANOVA on ranks with post-hoc Dunn's test, $\mathrm{p}<0.05$ ).

$10^{-8}-10^{-6} \mathrm{M}$, D-AP5: $10^{-5}-10^{-4} \mathrm{M}$ and CNQX: $10^{-7}-10^{-5} \mathrm{M}$ ), but not by the caspase inhibitors (DEVD-CHO: $10^{-7}-10^{-5}$ M, z-VAD-fmk: $10^{-5}-10^{-4} \mathrm{M}$, Fig 7).

\section{Effect of $4 \%$ oxygen on viability of cortical neurones}

Cultures were exposed to $0,0.5,1$ or $25 \mathrm{mM}$ glucosecontaining Neurobasal medium in hypoxic (4\% oxygen) conditions for various times. Following the exposure period, cultures were returned to $25 \mathrm{mM}$ glucosecontaining, normoxic medium $\left(20 \% \mathrm{O}_{2}\right)$ for the remainder of a $24 \mathrm{~h}$ period, after which time viability was assessed by means of fluorescence quantification of FITC-linked
A

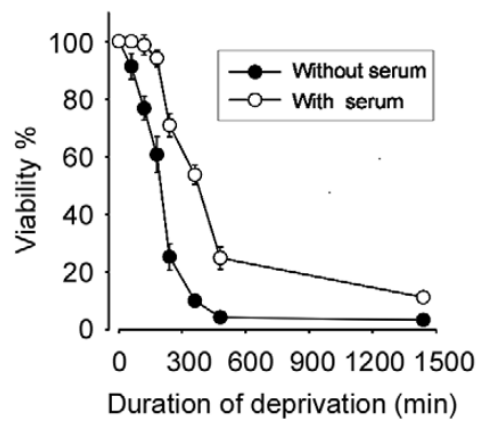

B

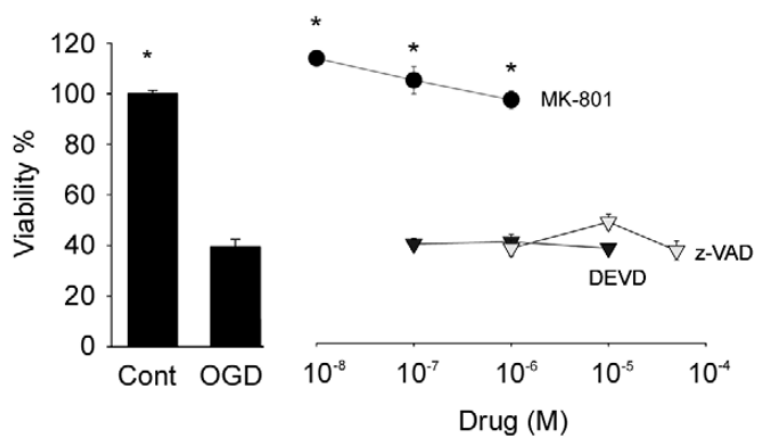

Fig 9. The viability of cultured rat cortical neurones and serum deprivation. (A) Rat cortical neurone cultures were exposed to $0 \mathrm{mM}$ glucose containing Neurobasal medium in either the presence or absence of serum in hypoxic $\left(4 \% \mathrm{O}_{2}\right)$ conditions for the times indicated. They were returned to normoxic, $25 \mathrm{mM}$ glucose-containing Neurobasal medium for the remainder of a $24 \mathrm{~h}$ period after which time viability was assessed by means of MAP-2 immunohistochemistry. Results shown are means \pm SE of 3 separate experiments comprising 12-24 wells in total. (B) Cultures were pre-treated with the drugs indicated (where DEVD $=$ DEVD-CHO and $z V A D=$ $\mathrm{z}$-VAD-fmk) for $30 \mathrm{~min}$ prior to $6 \mathrm{~h}$ exposure to $4 \% \mathrm{O}_{2}$ in glucosefree Neurobasal medium. Following the exposure period, cultures were returned to normoxic, normoglycaemic Neurobasal for $24 \mathrm{~h}$ prior to assessment of viability as previously described. Drugs were present throughout the exposure and recovery periods. Results show means \pm SE of 6-24 wells. "Value significantly greater than OGD group (One-way ANOVA with post-hoc Dunnett's test, $\mathrm{p}<0.05$ ).

MAP-2 immunohistochemistry.

Exposure to $4 \%$ oxygen produced a loss of viability at $24 \mathrm{~h}$ only if carried out in glucose-free medium (Fig 8A). Under these conditions, viability was reduced to $40 \%$ of control cultures following a $3 \mathrm{~h}$ exposure (exposure to $0 \mathrm{mM}$ glucose for $3 \mathrm{~h}$ did not produce a loss of viability in normoxic cultures) and total loss of viability was produced following a $6 \mathrm{~h}$ exposure. However, in cultures where glucose was present (even as low as $0.5 \mathrm{mM}$ ), no neuronal death occurred in response to exposure to $4 \%$ oxygen.

The effects of drugs (MK801: $10^{-8}-10^{-6} \mathrm{M}$, DEVD-CHO: $10^{-7}-10^{-5} \mathrm{M}$ or z-VAD-fmk: $10^{-5}-10^{-4} \mathrm{M}$ ) against a $3 \mathrm{~h}$ expo- 
sure to $4 \%$ oxygen, $0 \mathrm{mM}$ glucose were also studied (Fig $8 \mathrm{~B})$. Cultures were pre-treated for $30 \mathrm{~min}$ prior to OGD and were allowed to recover in normoxic, normoglycaemic Neurobasal medium for $48 \mathrm{~h}$ after exposure (drugs were present throughout). Exposure to $4 \%$ oxygen and $0 \mathrm{mM}$ glucose did not uncover any apoptotic component to OGDinduced cell death as again only MK801 significantly attenuated cell death.

\section{Effect of serum on viability of cortical neurones}

The presence of serum during OGD period $\left(4 \% \mathrm{O}_{2}, 0\right.$ $\mathrm{mM}$ glucose) prolonged neuronal viability (Fig 9A). With the addition of dialysed serum the $40 \%$ loss of viability observed with control cultures (without serum) after $3 \mathrm{~h}$ OGD was reduced to $<10 \%$. Nearly $6 \mathrm{~h}$ of OGD was required for serum-containing cultures to produce a comparable loss of viability.

The effect of NMDA receptor antagonists and caspase inhibitors against a $6 \mathrm{~h}$ exposure to $4 \%$ oxygen, $0 \mathrm{mM}$ glucose in the presence of dialysed serum were also studied to observe whether this modification would affect a relative increase in apoptotic cell (Fig 9B). The addition 30 min prior to OGD of MK-801 $\left(10^{-8}-10^{-6} \mathrm{M}\right)$ significantly prevented the $50 \%$. However, neither of the caspase inhibitors, DEVD-CHO $\left(10^{-7}-10^{-5} \mathrm{M}\right)$ or $\mathrm{z}-\mathrm{VAD}$. fmk $\left(10^{-6}\right.$ $\left.-10^{-4} \mathrm{M}\right)$, prevented the loss of cell viability. Similar results were observed if the exposure time was extended to $8 \mathrm{~h}$, although extending the OGD exposure to $16 \mathrm{~h}$ resulted in the failure of even MK-801 to prevent the cell death (data not shown).

\section{DISCUSSION}

Recent studies have demonstrated that following an episode of stroke-like focal cerebral ischaemia in vivo, neurones die by both apoptotic and necrotic mechanisms $[17,20,21]$. In middle cerebral artery (MCA) occlusion (the most common occlusion in stroke patients), the epicentre of the insult is the striatum, an area in the core of the MCA blood supply territory. In animal models, neurones within this region predominantly necrose 24 to $48 \mathrm{~h}$ after the occlusion of the blood vessel[22, 23]. The cortical region at the fringes of the MCA territory, with limited ancillary microvascular perfusion of nutrients from surrounding tissue[24-26], has been shown in some studies to provide an environment in which apoptosis can predominate[3-7, 11, 12, 27]. From a therapeutic viewpoint, these apoptotic cortical neurones provide the greatest opportunity for intervention and a number of studies have examined the efficacy of compounds targeted against the apoptotic cascade[8, 28, 29]. However, despite the versatility cortical cell culture offers in expanding the understanding of the ischaemic process or in screening for po- tential compounds, there is to date no consistent, characterised model of focal cerebral ischaemia in vitro with both an apoptotic and necrotic component.

The aim of this work was to characterise an in vitro protocol using oxygen-, glucose- or combined oxygenglucose-deprivation to mimic the mechanisms of neuronal cell death observed in focal stroke models. To ensure parity with in vivo focal models, the cultures were established from cerebrocortical tissue. With the inherent differences between cortical and hippocampal sensitivity to ischaemia[30-32], utilising undifferentiated forebrain cultures containing both hippocampal and cortical neurones to elucidate focal cerebral ischaemic pathophysiology, would be unlikely to provide an accurate representation of the in vivo disorder. This is highlighted by BossenmeyerPourie et al[33, 34] who showed that $6 \mathrm{~h}$ of hypoxia (without any glucose reduction) was sufficient to induce apoptosis in $20-25 \%$ of the cells in forebrain culture after $96 \mathrm{~h}$. During this time-period, necrosis only increased by $10-15 \%$, a profile much more reminiscent of a global/hippocampal model of ischaemia[33, 34].

Initial experiments were designed to establish controls for both neuronal necrosis (excitosis) and apoptosis (Fig 1). NMDA was added to cultures to produce a purely excitotoxic form of cell death. As expected $[35,36]$ cell viability was maintained in these cultures with the addition of the NMDA receptor antagonist, MK-801. MK-801 as well as AP5 used in later experiments, have both been shown to be good markers of glutamate-mediated excitotoxic cell death[37-40]. Staurosporine was utilised to induce an insult likely to be apoptotic in nature[19] in order to determine appropriate ways of assaying apoptosis in these cerebrocortical cells. Staurosporine-induced cell death corresponded with the activation of caspase-3-like caspases involved in the apoptotic cascade, but not those associated with the inflammatory response (caspase-1-like caspases, Fig 2).

Initial glucose-only deprivation showed that cortical cells could withstand low glucose concentrations for a sustained period (data not shown). However, with the combined absence of oxygen, $0.5 \mathrm{mM}$ glucose produced a reproducible loss of $40-60 \%$ of the neurones after a $3 \mathrm{~h}$ exposure (Fig 3). This exposure time correlates well with in vivo studies which routinely use an occlusion period of 2-3 $\mathrm{h}$ to induce infarction[28, 41-43]. However, this insult did not directly increase the activity of group II caspases (Fig 4), although again a high background was observed in control A1.1 cell extracts. The caspase-specific inhibitors (the group II inhibitor DEVD-CHO and the broad spectrum caspase inhibitor z-VAD-fmk) also failed to uncover a caspase component (Fig 5). Caspase inhibitors were deliberately chosen as a less robust marker of 
apoptosis than for example morphology. Caspase inhibitors (such as z-VAD) have previously been shown to be able to discriminate between apoptosis and NMDA-mediated necrosis [44] and caspase-3 activity has been tightly linked to both DNA fragmentation and cell shrinkage[45]. However, some caspase activity (amenable to caspase inhibition) has been observed in necrotic cells under certain conditions[45]. Morphological analysis of cellular appearance is therefore a crucial tool to confirm the presence of apoptosis. However, due to the lack of apoptosis observed during OGD in this study using less robust pharmacological tools, confirmation (of a non-occurring event) was not required.

Reducing the OGD exposure time to $60 \mathrm{~min}$ did provide conditions in which DEVD-CHO (but not z-VAD-fmk) displayed slight protection (Fig 6). The NMDA receptor antagonists used (either MK-801 or D-AP5) sustained neuronal viability under both conditions (Fig 5,6). This suggests that both long and short exposure to OGD conditions produce an NMDA receptor-mediated excitotoxic insult with only a small apoptotic component at the shorter exposure time.

Neuronal death produced under the conditions above ( $0 \%$ oxygen, $0.5 \mathrm{mM}$ glucose) was fairly rapid (within 24 h) and may therefore be representative of the cell death occurring within the core of an infarct rather than the more slowly evolving death one might expect to observe in the 'penumbral' region in vivo. In a subsequent study the objective was to modify the model to simulate the cell death that may occur in the salvageable regions of an ischaemic brain and exacerbate the apoptotic component of cell death. To this effect the severity of the insult was moderated using gradual oxygen deprivation (Fig 7) or $4 \%$ oxygen rather than $0 \%$ oxygen (Fig 8 ). As with previous experiments, the $80 \%$ loss of viability associated with a gradual loss of $\mathrm{O}_{2}$ over a $6 \mathrm{~h}$ exposure period was prevented by those compounds acting at excitatory amino acid receptors (MK801, D-AP5 and CNQX). However, no effect was apparent with caspase inhibitors. Similar results were obtained in cultures maintained at $4 \% \mathrm{O}_{2}$ for the duration of OGD.

As use of in vitro models of hypoxic cell death has been criticised on the grounds that the culture medium used for these studies lacks the $\mathrm{Ca}^{2+}$ buffering capacity of the normal physiological milieu, exaggerating hypoxic damage[46], approaches were taken to reduce the severity of the insult by maintaining serum in the medium throughout the OGD period (Fig 9). Again the NMDA receptor antagonist MK-801, but neither of the caspase inhibitors prevented the loss of viability.

In the above studies, systematic alterations of the OGD protocol did not reveal a large apoptotic component to oxygen-glucose-deprived cell death in cortical neurones.
Modification of the severity insult designed to induce a protracted process of cell death also did not uncover an apoptotic component observed by other studies.

Of the literature observing OGD-induced apoptosis in cortical cells, most have used the characteristic fragmentation of DNA as the sole apoptotic indicator[14, 16]. However, similar OGD experiments on other CNS cell types have highlighted the unreliability of nuclear fragmentation, without either morphological endorsement or caspase activity, as a measurement of apoptosis per se $[47,48]$. Out with the confines of cell culture, other fields also have cautionary note on Terminal deoxynucleotidyl transferase-mediated biotin-dUTP nick-end labelling (TUNEL) specificity[49-52], arguing against its role as the sole determinant of the presence of apoptosis.

A number of studies utilising ultrastructural or morphological indicies have failed to show apoptotic characteristics after 55[55] or $60[53,54]$ min of OGD. Increasing OGD duration to $100 \mathrm{~min}$ in a similar mixed culture also did not give rise to any propidium-stained apoptotic cells [56]. Studies utilising caspase activation as an indication of apoptotic cell death, have also failed to demonstrate any increases in activity after either 60 [53] or $150 \mathrm{~min}$ [57] exposure to OGD. Another study which analysed apoptotic cell death using TUNEL combined with morphological analysis after 30-90 min exposure to OGD, found only a tiny proportion of the cells $(0.05 \%)$ underwent apoptosis by $48 \mathrm{~h}[58]$.

Gwag et al[15] has observed an increase in OGD-induced apoptosis following blockade of glutamate receptors, with MK-801 combined with CNQX both protecting cells and 'unmasking' an apoptotic component to cell death. However, without suitable controls, this increase in cell loss may simply be due to the known apoptosis-inducing ability of MK-801 itself shown by both Hwang et al[59] and Seo et al[60]. In the same study, Seo et al[60] observed that protection of cortical cells after 120 min OGD with complestin (a blocker of the glutamate receptor-mediated ionic influx rather than the receptor itself), did not result in a secondary loss of viability at the later timepoint.

The systematic in vitro approach employed by this study to characterise cell death following a period of OGD suggests that pure neuronal cortical cultures are liable to die exclusively by necrotic mechanisms. While this is in contrast to the in vivo situation of focal cerebral ischaemia, it is perhaps not surprising, due to the differences between the culture plate and the whole animal (such as the in vivo inflammatory response $[61,62]$ not replicated in vitro). It may ultimately be these differences between culture plate and whole animal systems that provide the insight into the nascence of the apoptotic cascade in vivo. 


\section{ACKNOWLEDGEMENTS}

This work was supported by a research grant from Fujisawa Pharmaceuticals Co Ltd Japan.

Received, Nov 5, 2003

Revised, Mar 23, 2004

Accepted, Apr 9, 2004

\section{REFERENCES}

1 Charriaut-Marlangue C, Remolleau S, Aggoun-Zouaoui D, BenAri Y. Apoptosis and programmed cell death: a role in cerebral ischemia. Biomed Pharmacother 1989; 52:264-9.

2 Davoli MA, Fourtounis J, Tam J, et al. Immunohistochemical and biochemical assessment of caspase- 3 activation and DNA fragmentation following transient focal ischemia in the rat. Neurosci 2002; 115:125-36.

3 Krupinski J, Lopez E, Marti E, Ferrer I. Expression of caspases and their substrates in the rat model of focal cerebral ischemia. Neurobiol Dis 2000; 7:332-42.

4 Le DA, Wu Y, Huang Z, et al. Caspase activation and neuroprotection in caspase-3- deficient mice after in vivo cerebral ischemia and in vitro oxygen glucose deprivation. Proc Natl Acad Sci USA 2002; 99:15188-93.

5 Li Y, Chopp M, Jiang N, Yao F, Zaloga C. Temporal profile of in situ DNA fragmentation after transient middle cerebral artery occlusion in the rat. J Cereb Blood Flow Metab 1995; 15:389-97.

6 Li Y, Chopp M, Jiang N, Zhang ZG, Zaloga C. Induction of DNA fragmentation after 10 to $120 \mathrm{~min}$ of focal cerebral ischemia in rats. Stroke $1995 ; \mathbf{2 6}: 1252-8$.

7 Linnik MD, Miller JA, Sprinkle-Cavallo J, et al. Apoptotic DNA fragmentation in the rat cerebral cortex induced by permanent middle cerebral artery occlusion. Mol Brain Res 1995; 32:116-24.

8 Wiessner C, Sauer D, Alaimo D, Allegrini PR. Protective effect of a caspase inhibitor in models for cerebral ischemia in vitro and in vivo. Cell Mol Biol 2000; 46:53-62.

9 DeGirolami U, Crowell RM, Marcoux FW. Selective necrosis and total necrosis in focal cerebral ischemia. Neuropathologic observations on experimental middle cerebral artery occlusion in the macaque monkey. J Neuropathol Exp Neurol 1984; 43:57-71.

10 van Lookeren Campagne M, Gill R. Ultrastructural morphological changes are not characteristic of apoptotic cell death following focal cerebral ischaemia in the rat. Neurosci Lett 1996; 213: 111-4.

11 Asahi M, Hoshimaru M, Uemura $\mathrm{Y}$ et al. Expression of interleukin-1 beta converting enzyme gene family and bcl-2 gene family in the rat brain following permanent occlusion of the middle cerebral artery. J Cereb Blood Flow Metab 1997; 17:11-8.

12 Plesnila N, Zinkel S, Amin-Hanjani S, et al. Function of BID -a molecule of the bcl-2 family- in ischemic cell death in the brain. Eur Surg Res 2002; 34:37-41.

13 Velier JJ, Ellison JA, Kikly KK, et al. Caspase-8 and caspase-3 are expressed by different populations of cortical neurons undergoing delayed cell death after focal stroke in the rat. J Neurosci 1999; 19:5932-41.

14 Bruer U, Weih MK, Isaev NK, et al. Induction of tolerance in rat cortical neurons: Hypoxic preconditioning. FEBS Lett 1997; 414: $117-21$.

15 Gwag BJ, Lobner D, Koh JY, Wie MB, Choi DW. Blockade of glutamate receptors unmasks neuronal apoptosis after oxygenglucose deprivation in vitro. Neurosci 1995; 68:615-9.

16 Ruscher K, Freyer D, Karsch M et al. Erythropoietin is a paracrine mediator of ischemic tolerance in the brain: evidence from an in vitro model. J Neurosci 2002; 22:10291-301.

17 Li Y, Powers C, Jiang N, Chopp M. Intact, injured, necrotic and apoptotic cells after focal cerebral ischemia in the rat. J Neurol Sci 1998; 156:119-32.

18 Pauwels PJ, van Assouw HP, Leysen JE, Janssen PA. $\mathrm{Ca}^{2+}$ mediated neuronal death in rat brain neuronal cultures by veratridine: protection by flunarizine. Mol Pharmacol 1989; 36: 525-31.

19 Koh JY, Wie MB, Gwag BJ et al. Staurosporine-induced neuronal apoptosis. Exp Neurol 1995; 135:153-9.

20 Charriaut-Marlangue C, Margaill I, Represa A, et al. Apoptosis and necrosis after reversible focal ischemia: an in situ DNA fragmentation analysis. J Cereb Blood Flow Metab 1996; 16:18694.

21 Chen J, Li Y, Wang L, Lu M, Chopp M. Caspase inbibition by Z-VAD increases the survival of grafted bone marrow cells and improves functional outcome after MCAo in rats. J Neurol Sci 2002; 199:17-24

22 Aspey BS, Taylor FL, Terruli M, Harrison MJ. Temporary middle cerebral artery occlusion in the rat: consistent protocol for a model of stroke and reperfusion. Neuropathol Appl Neurobiol 2000; 26:232-42.

23 Belayev L, Alonso OF, Busto R, Zhao W, Ginsberg MD. Middle cerebral artery occlusion in the rat by intraluminal suture. Neurological and pathological evaluation of an improved model. Stroke 1996; 27:1616-23.

24 Dawson DA, Ruetzler CA, Hallenbeck JM. Temporal impairment of microcirculatory perfusion following focal cerebral ischemia in the spontaneously hypertensive rat. Brain Res 1997; 749:200-8.

25 Olsen TS, Larsen B, Herning M, Skriver EB, Lassen NA. Blood flow and vascular reactivity in collaterally perfused brain tissue. Evidence of an ischemic penumbra in patients with acute stroke. Stroke 1983; 14:332-41.

26 Roussel SA, van Bruggen N, King MD, Gadian DG. Identification of collaterally perfused areas following focal cerebral ischemia in the rat by comparison of gradient echo and diffusionweighted MRI. J Cereb Blood Flow Metab 1995; 15:578-86.

27 Yuan Q, Li R, Yang H, Zhang G. Effects of reperfusion on neuronal changes and macrophagic response after transient focal ischemia - reperfusion of brain in rats. Hua Xi Yi Ke Da Xue Xue Bao 1999; 30:155-7.

28 Mouw G, Zechel JL, Zhou Y, et al. Caspase-9 inhibition after focal cerebral ischemia improves outcome following reversible focal ischemia. Metab Brain Dis 2002; 17:143-51.

29 Wang X, Wang H, Xu L, et al. Significant neuroprotection against ischemic brain injury by inhibition of the MEK1 protein kinase in mice: Exploration of potential mechanism associated with apoptosis. J Pharmacol Exp Ther 2003; 304:172-8.

30 Honkaniemi J, Massa SM, Breckinridge M, Sharp FR. Global ischemia induces apoptosis-associated genes in hippocampus. Mol Brain Res 1996; 42:79-88.

31 Nunn JA, LePeillet E, Netto CA, et al. Global ischaemia: Hippocampal pathology and spatial deficits in the water maze. Behav Brain Res 1994; 62:41-54.

32 Zhao G, Flavin MP. Differential sensitivity of rat hippocampal 
and cortical astrocytes to oxygen-glucose deprivation injury. Neurosci Lett 2000; 285:177-80.

33 Bossenmeyer-Pourie C, Koziel V, Daval JL. Effects of hypothermia on hypoxia-induced apoptosis in cultured neurons from developing rat forebrain: comparison with preconditioning. Pediatr Res 2000; 47:385-91.

34 Bossenmeyer-Pourie C, Lievre V, Grojean S, et al. Sequential expression patterns of apoptosis- and cell cycle-related proteins in neuronal response to severe or mild transient hypoxia. Neurosci 2002; 114:869-82.

35 Hartley DM, Choi DW. Delayed rescue of N-methyl-D-aspartate receptor-mediated neuronal injury in cortical culture. $\mathrm{J}$ Pharmacol Exp Ther 1989; 250:752-8.

36 Kirk CJ, Reddy NL, Fischer JB, et al. In vitro neuroprotection by substituted guani-dines with varying affinities for the Nmethyl-D-aspartate receptor ionophore and for sigma sites. $\mathrm{J}$ Pharmacol Exp Ther 1994; 271:1080-5.

37 MacGregor DG, Avshalumov MV, Rice ME. Brain edema induced by in vitro ischemia: causal factors and neuroprotection. $\mathrm{J}$ Neurochem 2003; 85:1402-11.

38 Moldrich RX, Cheung NS, Pascoe CJ, et al. Excitotoxic profile of LY339434, a GluR5 agonist, in cultured murine cortical neurons. Brain Res 2000; 862:270-5.

39 Sei Y, Fossom L, Goping G, Skolnick P, Basile AS. Quinolinic acid protects rat cerebellar granule cells from glutamate-induced apoptosis. Neurosci Lett 1998; 241:180-4.

40 Sohn S, Kim EY, Gwag BJ. Glutamate neurotoxicity in mouse cortical neurons: atypical necrosis with DNA ladders and chromatin condensation. Neurosci Lett 1998; 240:147-50.

41 Curras-Collazo MC, Patel UB, Hussein MO. Reduced susceptibility of magnocellular neuroendocrine nuclei of the rat hypothalamus to transient focal ischaemia produced by middle cerebral artery occlusion. Exp Neurol 2002; 178:268-79.

42 Dijkhuizen RM, Singhal AB, Mandeville JB et al. Correlation between brain reorganization, ischemic damage, and neurologic status after transient focal cerebral ischemia in rats: a functional magnetic resonance imaging study. J Neurosci 2003; 23:510-7.

43 McCarter JF, McGregor AL, Jones PA, Sharkey J. FK506 protects brain tissue in animal models of stroke. Transplant 2001; 33:2390-2.

44 Ko HW, Han KS, Kim EY, et al. Synergetic activation of p38 mitogen-activated protein kinase and caspase-3-like proteases for execution of calyculin A-induced apoptosis but not N-methyl-d-aspartate-induced necrosis in mouse cortical neurons. J Neurochem 2000; 74:2455-61.

45 Hetz CA, Hunn M, Rojas P, et al. Caspase-dependent initiation of apoptosis and necrosis by the Fas receptor in lymphoid cells: Onset of necrosis is associated with delayed ceramide increase. J Cell Sci 2002; 115:4671-83.

46 Kristian T, Siesjo BK. Calcium in ischemic cell death. Stroke 1989; 29:705-18.

47 Kaasik A, Vassiljev V, Poldoja E, Kalda A, Zharkovsky A. Do nuclear condensation or fragmentation and DNA fragmentation reflect the mode of neuronal death? Neuroreport 1999; 10:1937-42.

48 Kalda A, Eriste E, Vassiljev V, Zharkovsky A. Medium transitory oxygen-glucose deprivation induced both apoptosis and necrosis in cerebellar granule cells. Neurosci Lett 1998; 240: 21-24.

49 Charriaut-Marlangue C, Ben-Ari Y. A cautionary note on the use of the TUNEL stain to determine apoptosis. Neuroreport 1995; 7:61-4.

50 de Torres C, Munell F, Ferrer I, Reventosand J, Macaya A. Identification of necrotic cell death by the TUNEL assay in the hypoxic-ischemic neonatal rat brain. Neurosci Lett 1997; 230:14.

51 Grasl-Kraupp B, Ruttkay-Nedecky B, Koudelka H, et al. In situ detection of fragmented DNA (TUNEL assay) fails to discriminate among apoptosis, necrosis, and autolytic cell death: a cautionary note. Hepatology 1995; 21:1465-8.

52 Pulkkanen KJ, Laukkanen MO, Naarala J, Yla-Herttuala S. Falsepositive apoptosis signal in mouse kidney and liver detected with TUNEL assay. Apoptosis 2000; 5:329-33.

53 Lobner D, Choi DW. Preincubation with protein synthesis inhibitors protects cortical neurons against oxygen-glucose deprivation-induced death. Neurosci 1996; 72:335-41.

54 Moroni F, Meli E, Peruginelli F, et al. Poly (ADP-ribose) polymerase inhibitors attenuate necrotic but not apoptotic neuronal death in experimental models of cerebral ischemia. Cell Death Differ 2001; 8:921-32.

55 Goldberg MP, Choi DW. Combined oxygen and glucose deprivation in cortical cell culture: calcium-dependent and calciumindependent mechanisms of neuronal injury. J Neurosci 1993; 13:3510-24.

56 Lobner D, Ali C. Mechanisms of $\beta$ FGF and NT-4 potentiation of necrotic neuronal death. Brain Res 2002; 954:42-50.

57 Gendron TF, Mealing GA, Paris J, et al. Attenuation of neurotoxicity in cortical cultures and hippocampal slices from E2F1 knockout mice. J Neurochem 2001; 78:316-24.

58 Wise-Faberowski L, Raizada MK, Sumners C. Oxygen and glucose deprivation-induced neuronal apoptosis is attenuated by halothane and isoflurane. Anesth Analg 2001; 93:1281-7.

59 Hwang JY, Kim YH, Ahn YH, Wie MB, Koh JY. N-Methyl-Daspartate receptor blockade induces neuronal apoptosis in cortical culture. Exp Neurol 1999; 159:124-30.

60 Seo SY, Yun BS, Ryoo IJ et al. Complestatin is a noncompetitive peptide antagonist of N-methyl-D-aspartate and alpha-amino3-hydroxy-5-methyl-4-isoxazolepropionic acid/kainate receptors: Secure blockade of ischemic neuronal death. J Pharmacol Exp Ther 2001; 299:377-84.

61 Tanaka R, Komine-Kobayashi M, Mochizuki H et al. Migration of enhanced green fluorescent protein expressing bone marrowderived microglia/macrophage into the mouse brain following permanent focal ischemia. Neurosci 2003; 117:531-9.

62 Tomita M, Fukuuchi Y. Leukocytes. Macrophages and secondary brain damage following cerebral ischemia. Acta Neurochir Suppl 1996; 66:32-9. 